\title{
Modelling How Managers Support Their Subordinates Toward Environmental Sustainability: A Moderated-Mediation Study
}

\author{
Pascal Paillé, Laval University, Canada \\ Jorge H. Mejía Morelos, HEC Montréal, Canada
}

\begin{abstract}
This study examines the linkages between managerial support for the environment, employee environmental commitment, perceived behavioral control, and employee propensity to recycle. Using a convenience sample $(N=$ 142), we report that employee environmental commitment mediates the relationship between managerial support and propensity to behave eco-friendly. Additionally, we showed that perceived behavioral control moderates the relationship between employee environmental commitment and propensity to recycle.
\end{abstract}

Keywords: Managerial Support; Employee Environmental Commitment; Propensity To Recycle; Perceived Behavioral Control; Moderated Mediation

\section{INTRODUCTION}

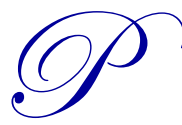

rotecting the environment is an important challenge that needs the engagement of multiple stakeholders (Jackson, 2012). Whereas the business sector impacts the natural environment significantly more than residential users (Davis \& Challenger, 2009), organizational settings are rarely investigated compared to those of the household or public spaces (Steg \& Vlek, 2009). This discrepancy leads to the observation that the current research effort on pro-environmental behavior is somewhat paradoxical. Our intention here is not to explain the reason of the scarcity of research in the workplace. Although it remains necessary to continue research on environmental issues in private sphere, it is also essential to develop more investigations in organizational contexts. Despite the current dearth of research, interest has been growing in individual efforts that contribute to environmental sustainability in the workplace, including organizational citizenship for the environment (Lamm, Tosti-Kharas, \& Williams, 2013), innovative environmental behaviors (Ramus \& Steger, 2000), energy conservation (Carrico \& Riemer, 2011; Lo, Peters \& Kok, 2012), and green behavior (Norton, Zacher \& Ashkanasy, 2014; Ones \& Dilchert, 2012). In this paper, we propose to carry on these efforts. In so doing, we report findings from a survey shedding light on employees' proneness to recycle at work.

Zibarras and Ballinger (2011) Indicated that "the most popular environmental initiative is the recycling of waste materials, with 86 per cent of organisations reporting that they have a recycling scheme in place" (p. 85). As noticed Klein and Huffman (2013) although "recycling is one of the lower-impact environmental sustainability behaviors, it still provides substantial savings to organizations" (p. 8). Surprisingly, whereas most prior research has addressed individuals' recycling behavior in non-work domains (e.g., Fiorillo , 2013; Hornik, Cherian, Madansky \& Narayana, 1995; Gillespie \& Bennett, 2013; Schultz, Oskamp \& Mainieri, 1995; Sidique, Lupi \& Joshi, 2010; Tucker \& Speirs, 2003), workplace recycling remains largely overlooked, with the exception of a handle of research (Austin, Hatfield, Grindle, \& Bailey, 1993; Brothers, Krantz \& McClannahan, 1994; Greaves, Zibarras \& Stride, 2013; Lee, De Young \& Marans, 1995; MacDonald, 2011; Price \& Pitt, 2012; Tudor, Barr, Gilg, 2007). Typically, these prior investigations on recycling in organizational settings have to a large extent put the emphasis on facilities, and revealed that maintaining employee willingness to use appropriate bins is an important challenge for organizations (Austin et al., 
1993; Brothers et al., 1994). However, relatively few research efforts have sought to put the focus on the variables that can contribute to maintain employee willingness to recycle. Tudor et al. (2007) suggested that employees may be encouraged to recycle when they are at job if the organization proposes relevant waste management policies, and also if these employees perceived environmental commitment among other organizational members. In this paper we contend that immediate managers, as organizational members, play an important role in this area. We posit that he or she may help employees maintain their recycling efforts. More specifically, we test a model, which proposes to examine to what extent perceived behavioral control moderates the indirect effect of perceived managerial support on employee's propensity to behave in eco-friendly way in the workplace through employee environmental commitment. In so doing, we contribute to advance knowledge on the drivers motivating employees towards sustainable behavior. Particularly, we offer results from a field study demonstrating that the employee's propensity to adopt recycling behavior in the workplace is fostered by support given by their immediate superior when they believe or perceive recycling is difficult to achieve.

\section{LITERATURE REVIEW AND HYPOTHESES}

\section{Effect of Supervisory Support on Environmental Sustainability in the Workplace}

Research in environmental sustainability has well documented how managerial support encourages employees toward environmentally responsible behavior (Daily, Bishop, \& Govindarajulu 2009; Gkorezis, 2015; Lülfs \& Hahn, 2013; Paillé, Boiral \& Chen, 2013; Ramus, 2001; Ramus \& Steger, 2000; Raineri \& Paillé, 2016; Ramus \& Killmer, 2007).

Ramus (2001) has found that employees are more likely to engage in environmental initiatives on the job when they perceive that their supervisor encourages new ideas, is open-minded, provides regular training to subordinates, shares critical information, rewards efforts, and shows a sense of responsibility. Zibarras and Ballinger (2011) surveyed 147 CEOs in the UK, and reported managerial support, senior management's commitment, and engagement from staff as the three main facilitators for pro-environmental actions. Although Ramus (2001), and Zibarras and Ballinger (2011) did not considered recycling specifically, their respective findings are useful, since according to Ones and Dilchert (2012) recycling in the job is a responsible behavior toward environment. Therefore, it may be inferred that may likely increase when they experience support from their managers.

Research on recycling in the workplace has rarely considered the role of immediate managers on the employees' propensity to recycle. Only a handle of research can be found in the relevant literature. Depending the specific question analyzed, available findings have typically focused on the degree to which employees have an access to facilities for sorting waste (Austin et al. 1993; Brothers et al. 1994; Price \& Pitt, 2012), or whether individual attitudes in private setting may be a good predictors when they are at work (Lee et al. 1995; MacDonald, 2011), or if advices from colleagues, or normative pressures contribute to shape the awareness about energy saving (Carrico \& Riemer, 2011; Zhang, Wang \& Zhou, 2013). Finally, relatively few research efforts have sought to put the focus on employee environmental commitment that can contribute to maintain employee willingness to adopt conservation behavior in work settings.

Tudor et al. (2007) found that employees may be encouraged to recycle at job if their organization proposes relevant waste management policies, and if these employees perceived that other organizational members are also committed to protect the environmental. Further research has gone beyond results by Tudor and his colleagues. In this regard, Raineri and Paillé (2016) have found that organizational citizenship behaviors for the environment are positively influenced by employee environmental commitment (Raineri \& Paillé, 2016). Given that recycling is conceived as a category of green behaviors (Ones \& Dilchert, 2012), a similar finding can be expected conserving and employee environmental commitment.

In summary, current literature supports the conclusion that managerial support can make the difference also in the particular context of recycling. Drawn upon prior research in the context of environmental sustainability, it seems consistent to assume a positive effect of supervisory support for the environment on employee environmental commitment that in turn has a positive influence on the individual proneness to engage in recycling. Therefore, 
Hypothesis 1: Employee environmental commitment mediates the positive relationship between managerial support and the propensity to recycle.

\section{The Moderating Effect of Perceived Behavioral Control}

Ajzen (1991) defines PBC as "people's perception of the ease or difficulty of performing the behavior of interest" (p. 183). PBC is typically associated with the Theory of Planned Behavior (TPB), which posits that for a given behavior, the proximal variable is the intention to perform this behavior, itself determined by three key variables that are the individual attitude toward the behavior, the pressure from other individuals, and the degree to which individuals believe that perform the behavior is easy or not. PBC helps to understand how individuals deal with their capacity to engage effort under their own judgment of autonomy (Boudewyns, 2013).

Ease or difficulty to engage in recycling behavior can be explained by internal or external factors (Hornik et al., 1995). While internal sources of control refer to individual knowledge, skills, and abilities, external sources of control are perceived aids or hindrances in the work environment, such as available facilities or cooperation with other persons (Kraft, Rise, Sutton \& Røysamb, 2005; Poškus, 2016). Prior research in the workplace indicated that facilities, and related information on how to use them, played a key function in facilitating recycling. Although, in these studies, investigators did not refer explicitly to $\mathrm{PBC}$, this research gave a good insight on how sources of control may explain to what extent individuals perform adequately recycling behavior. Austin et al. (1993)'s experimental research amongst academics showed that sign prompts help increase recycling behavior. Brothers et al. (1994) reported that proximity of facilities (trash, containers and bins) coupled with memos over time had a significant effect on employees' recycling behavior, diminishing the cost of trash removal. Price and Pitt (2012) confirmed these findings and claimed that location of available facilities affected non-recycling activities at work more than personal attitude toward the environment.

Recent research on recycling in the workplace has pointed out the role of PBC by including the two other components of TPB. The association of attitude with natural environments and social norm alongside PBC offered a means to improve the prediction of employee decision to recycle. Tudor et al. (2007) reported that low behavioral control in term of lack of time may affect healthcare employees' willingness to engage in sustainable waste management actions in their job. However, lack of time becomes insignificant when employees consider waste management an important issue and habitually reuse materials. Their findings indicated the attitude of (not) being "bothered" as a predictor. Greaves et al. (2013) confirmed that the best predictor of intention to recycle is general attitude toward the natural environment, found pressure from others a lesser factor, and found no effect for PBC. Interestingly, while lack of recycling facilities contributed to $\mathrm{PBC}$, time taken to separate waste and visit bins did not.

Examining the moderating role of easiness may help to improve understanding on how are related the employee commitment attitude toward the environmental and propensity to adopt conservation behavior. Little research has attempted to test this interaction effect, but some arguments support this assumption. Armitage and Conner (2001) suggested that $\mathrm{PBC}$ is less predictive of intention in situations where individuals have strong attitudes. In accordance with Yzer (2007) an "attitude can have a strong positive effect on intention if perceived control is high, and an attenuated effect if perceived control is low" (p. 117). Research on employee commitment has shown the necessity to take into account the degree to which an individual is committed toward a specific target for predicting relevant work behavior (Meyer \& Herscovitch, 2001). Klein, Molloy and Brinsfield (2012) argued that employees may be more committed toward a given target if they believe they have the necessary resources to control a situation and if they can perform work-related behavior. In a similar vein, Bingham, Mitchell, Bishop and Allen (2013) assume that the link between employee commitment to a cause and relevant behavior is affected by how much individuals believes they have sufficient judgment and ability to perform this relevant behavior. These propositions still to be tested in the environmental sustainability context, and specifically in the conserving context. Thus, based on above discussion regarding the role of perceived easiness (i.e., PBC) in sustainable contexts it seems reasonable to assume that an employee is more to engage recycling if on the one hand he or she demonstrates a high level of environmental commitment and, on the other hand, if he or she believes having sufficient resource. This means PBC may or not strengthen the indirect relationship between managerial support on the propensity to adopt recycling behavior through employee environmental commitment. Thus the following relationship can be expected. 
Hypothesis 2: Perceived behavioral control moderates the indirect relationship between perceived managerial support and propensity to adopt recycling behavior through employee environmental commitment. Specifically, employee environmental commitment will mediate the indirect effect of managerial support on propensity to adopt recycling behavior when perceived behavioral control is low but not when it is high.

\section{METHOD}

\section{Sample and Participants}

Participants comprised 142 full-time employees. A majority were men (72.5\%). The average age of all participants was 41.8 years $(\mathrm{SD}=8.1$ years). They indicated an average of 18.7 years $(\mathrm{SD}=10.5$ years) of global working experience. Finally, participants worked in different industries, including services $(29.3 \%)$, banking and finance $(19.3 \%)$, construction industry $(12.9 \%)$, information technology $(7.2 \%)$, automotive $(6.4 \%)$, health care $(4.3 \%)$, education $(2.1 \%)$, and other areas $(18.5 \%)$.

\section{Measurements}

Perceived managerial support was measured using a selection of statements identified by Ramus (2001) ( $\alpha=.92$; mean $=21.4 ; \mathrm{SD}=5.5)$. Perceived behavioral control was measured with the five-item scale based on Ajzen's statements (Ajzen, 2002). $(\alpha=.78$; mean $=17.4 ; \mathrm{SD}=3.2)$. Employee environmental commitment was measured with the scale developed by Raineri and Paillé $(2016)(\alpha=.95 ;$ mean $=25.2 ; \mathrm{SD}=5.8)$. Propensity to adopt recycling behavior was measured with four items borrowed from the scale developed by Lamm et al. (2013) for measuring organizational citizenship behavior for the environment $(\alpha=.71$; mean $=16.3$; $\mathrm{SD}=2.5)$.

All items were measured using a five-point Likert scale ranging from 1 (strongly disagree) to 5 (strongly agree).

According to previous research environmental variables (attitudes and behaviors) are sensitive to gender and age (Klein, D’Mello \& Wiernik, 2012 for review). Thus, gender and age were used as control variables.

\section{Data Analysis}

A confirmatory factor analysis (CFA) assessed the dimensionality of the data. We used Amos 19 (Arbuckle, 2009) and the maximum likelihood method of estimation. To assess the fit of model, we used the chi-squared, comparativefit index (CFI), root-mean-square error of approximation (RMSEA). Values between .05 and .08 for the RMSEA, and greater than .95 for CFI reflect good and acceptable data fits, respectively (Schermelleh-Engel, Moosbrugger, \& Muller, 2003). Finally, we computed also Akaike information criterion (AIC), because it offers the best baseline comparison (Burnham \& Anderson, 2002). According to Burnham and Anderson (2002), the model with the lowest AIC must be retained if the AIC difference is significant (i.e., at least comprised between 4 and 7).

Hypothesis 1 implied testing mediation. We tested this mediation effect (with $n=5,000$ bootstrap re-samples) by directly assessing whether the indirect effect of manager's support on propensity to adopt recycling behavior through employee environmental commitment is significantly different from zero (Preacher, Rucker \& Hayes, 2007).

Hypothesis 2 implied testing moderation in the context of mediation. Thus Hypothesis 2 was tested using conditional indirect effects that refer according to Preacher et al. (2007) to "the magnitude of an indirect effect at a particular value of a moderator" (or at particular values of more than one moderator)" (p. 186). Moderation in the context of mediation was performed through PROCESS macro. According to Hayes (2013) "PROCESS is a computational tool for path analysis-based moderation and mediation analysis as well as their integration in the form of a conditional process model" (p. 419). Conditional indirect effects are demonstrated if confidence intervals does not contain 0. 


\section{RESULTS}

\section{Testing Common Method Variance}

In the present study, the data were collected using self-report measures at one point of time. Therefore, we should warrant that bias due to common method variance (CMV) did not present a risk. Following Podsakoff, MacKenzie, Lee and Podsakoff (2003) the single-common-method-factor approach is an appropriate solution in the context of confirmatory factor analysis (CFA). According to Paillé and Boiral (2013) this "approach involves the inclusion of a common factor (latent variable) in the measurement model" (p. 122). The "measurement model" is compared with the "measurement model with common factor." CMV does not present a risk of bias if the measurement model fits the data better than its competing model. The baseline comparison is the same as for CFA.

Table 1. Results of Model Comparisons ( $\mathrm{N}=142)$

\begin{tabular}{|c|c|c|c|c|c|}
\hline Models & $\chi^{2}$ & df & CFI & RMSEA & AIC \\
\hline Null model & $2119.0^{* * *}$ & 190 & - & - & - \\
\hline Measurement model & $253.3^{* * *}$ & 161 & .95 & .06 & 351.3 \\
\hline Measurement model with common factor & $257.9^{* * *}$ & 160 & .94 & .07 & 357.9 \\
\hline
\end{tabular}

Notes: $* * * \mathrm{p}<.001$

Table 1 reports baseline comparison for the null model, the measurement model, and the measurement model with common factor. Measurement model and the measurement model with common factor have yielded the data well. However, based on the AIC comparison $(\triangle \mathrm{AIC}=6.5)$, we can deduce that bias due to CMV was not a serious threat.

\section{Confirmatory Factor Analysis}

The hypothesized four-factor model yielded a good fit to the data, $\chi 2(161)=253.3, \mathrm{p}<.001$, CFI $=.95$, RMSEA $=$ .06 , AIC $=351.3$ (Table 1). This model provided a better fit than a three-factor model, in which employee environmental commitment and supervisor support for the environment were combined $(\chi 2(165)=611.2, \mathrm{p}<.001$, $\mathrm{CFI}=.76, \mathrm{RMSEA}=.13, \mathrm{AIC}=701.2)$, or a one-factor model that merged all variables $(\chi 2(190)=918.6, \mathrm{p}<.001$, $\mathrm{CFI}=.61, \mathrm{RMSEA}=.17, \mathrm{AIC}=998.6)$. Thus, this means that respondents have distinguished all the variables of this study.

Table 2. Correlation matrix $(N=142)$

\begin{tabular}{|c|c|c|c|c|}
\hline & 1 & 2 & 3 & 4 \\
\hline 1. Managerial support & - & & & \\
\hline 2. Employee environmental commitment & $.38^{* *}$ & - & & \\
\hline 3. Perceived behavioral control & $.44^{* *}$ & $.24^{* *}$ & - & \\
\hline 4. Propensity to adopt recycling behavior & $.28^{* *}$ & $.29^{* *}$ & $.43^{* *}$ & - \\
\hline
\end{tabular}
Notes. ${ }^{* *} p<.01$.

\section{Testing Relationships}

Table 2 reports psychometric properties, as well as correlations among the variables. Results for Hypotheses 1 and 2 can be found in Table 2, Table 3 and Table 4, respectively.

Hypothesis 1 predicted a mediating effect of employee environmental commitment on the relationship between managerial support for the environment and propensity to adopt recycling behavior. Whereas the standardized direct effect was significant, as the $95 \% \mathrm{CI}$ did not contain $0(\beta=.299,95 \% \mathrm{CI}=.034, .306)$, the standardized indirect effect was also significant since the $95 \% \mathrm{CI}$ did not straddle $0(\beta=.045,95 \% \mathrm{CI}=.001, .126)$. These results lead to the conclusion that employee environmental commitment has played a mediating role between supervisor support and propensity to adopt recycling behavior. In addition it was estimated that the mediator explained $25.1 \%$ of the variance (indirect effect/total effect; .045/.179). Therefore, the data supported H1. 
Table 3. Results of moderated multiple regression (Hypothesis 2)

\begin{tabular}{c|l|c|c|c|c}
\hline \multirow{2}{*}{ Step } & Variable(s) entered & Model 1 & Model 2 & Model 3 & Model 4 \\
\hline \multirow{2}{*}{1} & Gender & .02 & -.01 & .02 & .01 \\
\hline & Age & .01 & -.05 & -.04 & .05 \\
\hline 2 & EEC & & $.36^{* * *}$ & $.23^{* *}$ & .17 \\
\hline 3 & PBC & & & $.35^{* * *}$ & $.35^{* * *}$ \\
\hline 4 & EEC x PBC & & & $.18^{*}$ \\
\hline & $\Delta R^{2}$ & .00 & $.12^{* * *}$ & $.10^{* * *}$ & $.03^{*}$ \\
\hline
\end{tabular}

Notes. ${ }^{* * *} \mathrm{p}<.001 ; * * p<.01 ; * \mathrm{p}<.05$. EEC, employee environmental commitment; PBC, perceived behavioral control

Hypothesis 2 predicted that $\mathrm{PBC}$ would moderate the indirect effect of perceived managerial support on propensity to adopt recycling behavior through employee environmental commitment. Following Cohen, Cohen, West and Aiken (2003), the product terms (ECE x PBC) have been mean-centered to avoid multicollinearity. Findings are reported in Table 3. Model 4 indicated that employee environmental commitment and PBC interacted negatively in the prediction of propensity to adopt recycling behavior $\left(\beta=-.18, \mathrm{p}<.05, \Delta \mathrm{R}^{2}=.03\right)$.

Table 4 reports the conditional indirect effects of perceived managerial support on propensity to adopt recycling behavior through employee environmental commitment at low and high values of PBC. Whereas data indicate this conditional effect is significant at a low level of $\mathrm{PBC}(.021,95 \% \mathrm{CI}=.0001, .0587)$, is not significant at high level of it, since CI contains $0(-.002,95 \% \mathrm{CI}=-.0310, .0307)$.

Table 4. Conditional indirect effect(s) of managerial support on propensity to adopt recycling behavior at the values of perceived behavioral control (PBC)

\begin{tabular}{l|c|c|c|c|}
\hline \multicolumn{1}{c}{ Level of PBC } & Effect & Standardized error & Lower & 95\% CI \\
\hline Low (1 SD below the mean) & .021 & .014 & .0001 & Upper \\
\hline Medium (the mean) & .009 & .010 & -.0065 & .0587 \\
\hline High (1 SD above the mean) & -.002 & .015 & -.0310 & .0344 \\
\hline
\end{tabular}

Finally, a test was performed for assessing to what extent slopes are or not significantly different regarding high vs. low levels of PBC. Results show that the slope of the relationship between employee environmental commitment and propensity to adopt recycling behavior was relatively strong for employees who perceive low behavioral control (simple slope $=0.38, \mathrm{t}=2.018, \mathrm{p}<.05$ ), whereas the slope was relatively weak for those who perceived high behavioral control (simple slope $=-0.06, \mathrm{t}=0.833, \mathrm{p}=\mathrm{ns}$ ). Therefore, these results gave support for $\mathrm{H} 2$.

\section{DISCUSSION AND CONCLUSION}

\section{Findings}

This paper investigated whether employees committed to the environmental cause are more prone propensity to adopt recycling behavior when they believe they are supported by their immediate manager supports it, and to test the extent to which $\mathrm{PBC}$ affects their proneness propensity to adopt recycling behavior (i.e., intention to recycle). An employeelevel field study examined these propositions. Our data supported the two hypotheses. We found that employee environmental commitment mediated the effect of managerial support for the environment on propensity to adopt recycling behavior. We also found $\mathrm{PBC}$ moderates the relationship between employee environmental commitment and propensity to adopt recycling behavior. The paper adds to current environmental literature in several ways.

The first result of interest is that our research sheds light on the role of manager in the context of recycling in the workplace. With the notable exception of Humphrey, Bord, Hammond and Mann (1977)'s early experimental research, the role of managers in recycling remains neglected. They revealed that managerial encouragement had a positive, though slight, effect on waste separation quality. However, they did not explain the underlying process through which manager's encouragement transfers its positive effect on propensity to adopt recycling behavior. We have assumed 
that employee environmental commitment may intervene as an underlying psychological process to motivate employee recycling under managerial support. In accordance with our first hypothesis, we found that managerial support does increase employee environmental commitment, which in turn enhances propensity to recycle. Environmental support from the manager may be an external incentive in the workplace, since if managers are concerned by the necessity to protect the natural environment, by supporting their subordinates, they can imply a responsible attitude toward the environment.

From a broader perspective, we supported the contention of Tudor, Barr and Gilg, (2007), who posited that organizational members could shed more light on employee willingness to engage in recycling activities on the job. At his or her own level, an employee may interact with a wide range of people within the workplace, such as colleagues, peers, and immediate managers. Our paper has focused on immediate managers. Employee environmental commitment may strengthen the alignment between an employee and his or her manager, if they share the same environmental values. This is consistent with the social exchange framework. If managers seek to improve waste management, they should make environmentally supportive decisions that promote recycling.

Secondly, although Ajzen (1991) assumed that the effect of attitude on behavior is moderated by PBC, such effect remains little-examined in the context of sustainability. Methodological considerations have often been put forward for explaining the difficulties to assess moderating effect of PBC (Yver, 2007). Following Yver (2007) who suggested moderation analysis by using multiple regression, the current research tests PBC's interaction effect. Our findings indicate that the manner in which $\mathrm{PBC}$ affects the propensity to recycle in the workplace is best understood by taking into account the level of employee environmental commitment. Whereas at high level of environmental commitment, employees with high PBC did not differ significantly in their willingness to recycle from those with low PBC, at low level of environmental commitment, employees with low $\mathrm{PBC}$ are less prone to recycle in comparison with those who reported high PBC. This means that when individuals are committed toward the environment, they are less sensitive to lack of perceived behavioral control. Some prior research in the workplace examines the relationships between PBC and many pro-environmental behaviors, including prevention pollution, carpooling, energy conservation, switching computers off, and videoconferencing in place of travel (Cordano \& Frieze, 2000; Greaves et al., 2013; Laudenslager, Holt \& Lofgren, 2004; Boiral, Talbot \& Paillé, 2015). In these investigations, PBC was examined as an additive factor for predicting relevant behavioral intent toward the environment, and scholars did not consider to what extent level of PBC may explain pro-environmental behavior. For example, Greaves et al. (2013) reported that PBC was not associated with intention to recycle on the job, whereas attitude and perceived norms were not. Their findings suggested that the effect of PBC on intention to recycle has been overshadowed by the two other components. Hence, it remains difficult to determine how exactly individuals deal with low or high levels of behavioral control. Our findings help overcome this gap.

\section{Practical Implications}

Our research indicates that when immediate managers support environmental issues, their subordinates increase their propensity to recycle. Given the positive economic impact of recycling activities for organizations (Klein \& Huffman, 2013), the role of immediate managers cannot be neglected. This means that top management should give immediate managers greater autonomy to manage the resources at their disposal. By doing so, they strengthen immediate managers' credibility among employees (Paillé et al., 2013).

Our findings also show that when employees display a low degree of environmental commitment they are less prone to adopt recycling behavior, regardless of their perception of behavioral control. It seems thus necessary to increase the sense of environmental commitment among employees. One way to achieve this objective is to define environmental sustainability as an explicit organizational goal, since it contributes to the alignment of environmental values among staff (Mesmer-Magnus, Viswesvaran \& Wiernik, 2012). Another way is to raise the environmental concern among employees. That can be done by employee education through dedicated training sessions about environmental issues (Muros, Impelman \& Hollweg, 2012). 


\section{Limitation and Future Research}

Finally, despite its contributions, the present investigation is not without limitations. First, given the cross-sectional design of our research, the potential lack of generalizability of our findings cannot be neglected. Our research may be affected by a wide range of variables. Therefore, it could be useful to replicate this research model in other contexts. Also, given the specific objective of our investigation, we have not taken into account whether employees had access to recycling facilities, time to manage their own waste at work, or relevant knowledge. Therefore, we recognize that it is difficult to attribute the source of lack of behavioral control. To provide more accurate data, subsequent research might integrate determinants of perceived behavioral control. A third potential limitation is that we have regarded the employee propensity to recycle, and have not considered whether participants distinguish the nature of waste. This lack of precision may affect the results. Future research should take into account the nature of waste.

\section{AUTHOR BIOGRAPHIES}

Pascal Paillé is a full professor at Laval University. He is the Director of the PhD and Master Research Program of Faculty of Business Administration. His research focuses on employee retention, green human resource management, and pro-environmental behaviors at job. His research has been published in the Journal of Business Ethics, Journal of Business Research, International Journal of Human Resource Management, Journal of Environmental Psychology, Business, Strategy and the Environment, Journal of Applied Business Research, among others.

Jorge H. Mejía Morelos is an associate professor in the Department of Entrepreneurship and Innovation at HEC Montréal. His research focuses on Entrepreneurship, and Strategy. His research appears in the Journal of Business Ethics, Career Development International, Journal of Environmental Psychology, European Management Journal, among others.

\section{REFERENCES}

Ajzen, I. (1991). The theory of planned behavior. Organizational Behavior and Human Decision Processes, 50, $179-211$.

Ajzen, I. (2002). Perceived behavioral control, Self-Efficacy, locus of control, and the theory of planned Behavior1. Journal of Applied Social Psychology, 32(4), 665-683.

Arbuckle, J. (2009) Amos 5.0. Update to the Amos. User's Guide. SmallWaters Corporation, Chicago, IL.

Armitage, C. J., \& Conner, M. (2001). Efficacy of the theory of planned behavior: A meta-analytic review. British Journal of Social Psychology, 40, 471-499.

Austin, J., Hatfield, D. B., Grindle, A. C., \& Bailey, J. (1993). Increasing recycling in office environments. Journal of Applied Behavior Analysis, 26, 247-253.

Bingham, J. B., Mitchell, B. W., Bishop, D. G., \& Allen, N. J. (2013). Working for a higher purpose: A theoretical framework for commitment to organization-sponsored causes. Human Resource Management Review, 23(2), 174-189.

Boiral, O., Talbot D., \& Paillé, P. (2015). Leading by example: How managers can influence environmental practices. Business, Strategy and the Environment, 24, 532-550.

Boudewyns, V. (2013). A Meta-analytical test of perceived behavioral control interactions in the Theory of Planned Behavior. Unpublished Doctoral dissertation. University of Maryland.

Brothers, K., Krantz, P. \& McClannahan, L. (1994). Office paper recycling: A function of container proximity. Journal of Applied Behavior Analysis, 27, 153-160.

Burnham, K. P., and D. R. Anderson. 2002. Model selection and multimodel inference: a practical information-theoretic approach. Springer, New York.

Carrico, A.R. \& Riemer, M. (2011). Motivating energy conservation in the workplace: An evaluation of the use of group-level feedback and peer education. Journal of Environmental Psychology, 31, 1-13.

Cohen, J., Cohen, P., West, S. G., \& Aiken, L. S. (2003). Applied multiple regression/correlation analysis for the behavioral sciences, 3rd ed. Hillsdale: Erlbaum.

Cordano M, Hanson Frieze I. (2000). Pollution reduction preferences of U.S. environmental managers: applying Ajzen's theory of planned behavior. Academy of Management Journal, 43, 627-641.

Daily, B.F., Bishop, J.W., \& Govindarajulu, N. (2009). A Conceptual Model for Organizational Citizenship Behavior Directed Toward the Environment. Business \& Society, 48(2) 243-256.

Davis, M. C., \& Challenger, R. (2009). Climate change - Warming to the task. The Psychologist, 22, 112-114.

Fiorillo, D. (2013). Household waste recycling: national survey evidence from Italy. Journal of Environmental Planning and Management, 56(8) 1125-1151. 
Gillespie, R. \& Bennett, J. (2013). Willingness to pay for kerbside recycling in Brisbane, Australia. Journal of Environmental Planning and Management, 56(3) 362-377.

Gkorezis, P. (2015). Supervisor support and pro-environmental behavior: The mediating role of LMX. Management Decision, 53(5), 1045-1060.

Greaves, M., Zibarras, L. \& Stride C. (2013). Using the theory of planned behavior to explore environmental behavioral intentions in the workplace. Journal of Environmental Psychology, 34, 109-120.

Hayes, A. F. (2013). Introduction to Mediation, Moderation and Conditional Process Analysis. The Guilford Press, New-York, NY.

Hornik, J., Cherian, J., Madansky, M., \& Narayana, C. (1995). Determinants of recycling behavior: A synthesis of research results. The Journal of Socio-Economics, 24, 105-127.

Humphrey, C. R., Bord, R. J., Hammond, M. M., \& Mann, S. H. (1977). Attitudes and conditions for cooperation in a paper recycling program. Environment and Behavior, 9, 107-124.

Jackson, S.E. (2012). Portrait of a Slow Revolution Toward Environmental Sustainability. In S. E. Jackson, D.S. Ones, \& S., Dilchert (Eds.), Managing Human Resource for Environmental Sustainability (pp. 3-20). San Francisco, CA: JosseyBass.

Klein, H. J., Molloy J., \& Brinsfield, C. (2012). Reconceptualizing workplace commitment to redress a stretched construct: Revisiting assumptions and removing confounds. Academy of Management Review, 37 (1), 130-151.

Klein, R. M., D’Mello S., and Wiernik, B. M. (2012). Demographic Characteristics and Employee Sustainability. In S. E. Jackson, D.S. Ones, \& S., Dilchert (Eds.), Managing Human Resource for Environmental Sustainability (pp. 117-154). San Francisco, CA: Jossey-Bass.

Klein, S. R. \& Huffman, A. H. (2013). I-O Psychology and environmental sustainability in organizations: A natural partnership (p. 3-16). In Huffman, \& A. H. Klein, S. R. (Eds.) Green Organizations Driving Change with I-O Psychology NewYork, NY: Routledge.

Kraft, P., Rise, J. Sutton, S. \& Røysamb, E. (2005). Perceived difficulty in the theory of planned behaviour: Perceived behavioural control or affective attitude? British Journal of Social Psychology, 44, 479-496

Lamm, E., Tosti-Kharas, J., Williams, E. G. (2013). Read this article, but don't print it: Organizational citizenship behavior toward the environment. Group \& Organization Management, 38, 163-197.

Laudenslager, M. S., Holt, D. T., \& Lofgren, S. T. (2004). Understanding air force members' intentions to participate in proenvironmental behaviors: An application of the theory of planned behavior. Perceptual and Motor Skills, 98, $1162-$ 1170 .

Lee, Y. J., DeYoung, R., \& Marans, R. W. (1995). Factors influencing individual recycling behavior in office settings-A study of office workers in Taiwan. Environment and Behavior, 27, 380-403.

Lo, S.-H., Peters, G.-J. \& Kok, G. (2012). A Review of determinants and interventions for proenvironmental behaviors in organizations. Journal of Applied Social Psychology 42, 2933-2967.

Lülfs, R. \& Hahn R. (2013). Corporate greening beyond formal programs, initiatives, and systems: a conceptual model for voluntary proenvironmental behavior of employees. European Management Review, 10, 83-98.

MacDonald, R. (2011). Green behaviour: Differences in recycling behaviour between the home and the workplace. In D. Bartlett (Ed.), Going green: The Psychology of Sustainability in the Workplace (pp. 59-64). Leicester, England: British Psychological Society.

Mesmer-Magnus, J., Viwsevaran, C. \& Wiernik, B. M. (2012). The role of commitment in bridging the gap between organizational sustainability and environmental sustainability. In, Jackson, S. E., Ones, D. S., and S., Dilchert (Éds.) Managing Human Resources for Environmental Sustainability (pp. 155-186), San Francisco, CA: Jossey-Bass.

Meyer, J. P., \& Herscovitch, L. (2001). Commitment in the workplace: Toward a general model. Human Resource Management Review, 11, 299-326.

Muros, J. P., Impelman, K. \& Hollweg, L. (2012). Sustainability in coffee sourcing and implications for employee engagement at Caribou Coffee. In S. E. Jackson, D.S. Ones, \& S., Dilchert (Eds.), Managing Human Resource for Environmental Sustainability (pp. 375-403). San Francisco, CA: Jossey-Bass.

Norton, T. A., Zacher, H., \& Ashkanasy, N. M. (2014). Organisational sustainability policies and employee green behaviour: The mediating role of work climate perceptions. Journal of Environmental Psychology, 38, 49-54.

Ones, D., \& Dilchert, S. (2012). Environmental sustainability at work: A call to action. Industrial and Organizational Psychology, 5, 444-466.

Paillé P. \& Boiral O. (2013). Pro-environmental behavior at work: construct validity and determinants. Journal of Environmental Psychology, 36, 118-128.

Paillé P., Boiral O. \& Chen, Y. (2013). Linking environmental management practices and organizational citizenship behavior for the environment: a social exchange perspective. International Journal of Human Resource Management, 24(18), 35523575 .

Podsakoff, P. M., MacKenzie, S. B., Lee, J.-Y., \& Podsakoff, N. P. (2003). Common method biases in behavioral research: A critical review of the literature and recommended remedies. Journal of Applied Psychology, 88, 879-903.

Poškus, M. S. (2016). Investigating pro-environmental behaviors of Lithuanian University students. Current Psychology, 1-9. DOI: $10.1007 / \mathrm{s} 12144-016-9506-3$ 
Preacher, K. J., Rucker, D. D., \& Hayes, A. F. (2007). Addressing moderated mediation hypotheses: Theory, methods, and prescriptions. Multivariate Behavioral Research, 42(1), 185-227.

Price, S. \& Pitt, M. (2012). The influence of facilities and environmental values on recycling in an office environment. Indoor Built Environment, 21, 622-632.

Raineri, N. \& Paillé, P. (2016). Linking corporate policy and supervisory support with environmental citizenship behaviors: The role of employee environmental beliefs and commitment. Journal of Business Ethics, 137(1), 129-148.

Ramus, C. (2001). Organizational support for employees: Encouraging creative ideas for environmental sustainability. California Management Review, 43, 85-105.

Ramus, C. \& Steger, U. (2000). The roles of supervisory support behaviors and environmental policy in employee eco-initiatives at leading-edge European companies. Academy of Management Journal, 43, 605-626.

Ramus, C. A., \& Killmer, A. B. (2007). Corporate greening through prosocial extrarole behaviours - a conceptual framework for employee motivation. Business Strategy and the Environment, 16(8), 554-570.

Schermelleh-Engel, K., Moosbrugger, H., \& Muller, H. (2003). Evaluating the fit of structural equation models: Tests of significance and descriptive goodness-of-fit measures. Methods of Psychological Research Online, 8, $23-74$.

Schultz, P. W., Oskamp, S., \& Mainieri, T. (1995). Who recycles and when? A review of personal and situational factors. Journal of Environmental Psychology, 15, 105-121.

Sidique, S.F., Lupi, F., Joshi, S.V. (2010). The effects of behavior and attitudes on drop-off recycling activities. Resources, Conservation and Recycling, 54, 163-170.

Steg, L. \& Vlek, C. (2009). Encouraging pro-environmental behaviour: An integrative review and research agenda. Journal of Environmental Psychology, 29, 309-317.

Tucker, P. \& Speirs, D. (2003). Attitudes and behavioural change in household waste management behaviours. Journal of Environmental Planning and Management, 46(2), 289-307.

Tudor, T.L. Barr, S.W. Gilg, A.W. (2007). Linking intended behaviour and actions: A case study of healthcare waste management in the Cornwall NHS. Resources, Conservation and Recycling, 51, 1-23.

Yzer, M. (2007). Does perceived control moderate attitudinal and normative effects on intention? A review of conceptual and methodological issues. In I. Ajzen, D. Albarracin \& R. Hornik (Eds.) Prediction and change of health behavior: Applying the reasoned action approach (107-123). Mahwah, N-J. Laurence Erlbaum.

Zhang, Y., Wang, Z., \& Zhou, G. (2013). Antecedents of employee electricity saving behavior in organizations: An empirical study based on norm activation model. Energy Policy, 62, 1120-1127.

Zibarras, L., \& Ballinger, C. (2011). Promoting environmental behaviour in the workplace: A survey of UK organisations. In D. Bartlett (Ed.), Going green: The Psychology of Sustainability in the Workplace (pp. 84-90). Leicester, England: British Psychological Society. 